\title{
LA VIDA COMO ARTE Y EL ARTE COMO VIDA
}

\author{
Gaspar Brahm Mir \\ Universidad de Navarra
}

\begin{abstract}
Resumen: El hombre es un ser que busca el sentido de su existencia en todo lo que hace. A la vez que es consciente de su contingencia, es capaz de elevarse por sobre lo meramente temporal. El arte pareciera ser una actividad humana que, por combinar lo contingente con lo necesario, puede llevar al hombre hacia una obra llena de sentido. Siguiendo al teólogo suizo Hans Urs von Balthasar, cabría entender la vida del hombre como una obra artístico-dramática, en la que entran en diálogo su libertad con la donación divina. La obra maestra existencial será, por consiguiente, la aceptación plena del don de Dios por parte del hombre.
\end{abstract}

Palabras claves: arte, vida, existencia, sentido, fe, libertad, reflexión.

\section{Life as Art and Art as Life}

Abstract: Man, in all his activity, is a being in constant search of the meaning of his existence. Although aware of his contingency, he is able to raise his gaze above that which is merely temporal. Art seems to be a human activity which, combining that which is contingent with that which is necessary, leads man towards a masterpiece which is full of meaning. According to the Swiss Theologian Hans Urs von Balthasar, the life of man can be understood as an artistic-dramatic work, which puts into dialogue man's freedom and divine selfdonation. The existential masterpiece would therefore be the complete acceptance of the gift of God by man.

Keywords: Art, Life, Existence, Meaning, Faith, Freedom, Reflection.

Recibido: 12/3/2017 Aceptado: 10/6/2017 
Hay tiempos para hablar y tiempos para callar. De forma negativa lo expresaba la escritora Herta Müller con su frase: "cuando callamos nos volvemos incómodos, $[. .$.$] cuando hablamos nos volvemos ridículos". { }^{1}$ Esta premisa también tiene su validez para estas palabras: siempre cabe la posibilidad cierta de que lo escrito no sirva más que para hacerle perder el tiempo a sus lectores, por mucho que el autor sienta la necesidad de escribirlas y, no en pocos casos, afirme también su utilidad o su sentido estético.

Algo similar ocurre con las demás acciones de toda vida humana. E1 vértigo que existe entre el hacer y el dejar de hacer, el péndulo que oscila entre las diversas posibilidades del actuar, la indecisión fundamental que sumerge a uno en el mar de lo que todavía no se es, la melancolía de un pasado con aspiraciones que ya no podrán realizarse nunca; todas estas son experiencias profundas de la condición humana, enraizada en el devenir del tiempo, y compuesta de una combinación de fortuitos acontecimientos de todo tipo con intentos por salir a flote en el momento oportuno. Todo actuar está circundado por las sombras de la gracia y de la desgracia. Muchas veces son otros los que siembran, mientras uno cosecha; hay momentos en los que se siembra sin obtener fruto alguno. Otras veces, ni siquiera se tienen semillas. Y, sin embargo, aunque quizás sería más fácil quedarse inmóvil, se actúa.

Por una parte, está el deseo de jugar a la lotería y ganar, de pronto, el premio mayor; el todo o la nada. Pero todo hombre es también demasiado consientes de la fragmentación de su existencia, de su cotidianidad y, en de-

${ }^{1}$ Müller, 1994: 7: „Wenn wir schweigen, werden wir unangenehm, sagte Edgar, wenn wir reden, werden wir lächerlich“. 
finitiva, de que sin importar lo que haga, siempre llegará un futuro implacable para sumergirlo en su corriente y hacerlo partícipes de una cadena en movimiento que tiende hacia el infinito. Es la experiencia de Eliot, el poeta inglés, expresada en sus Cuatro cuartetos: "No hay fin, sólo suma: horas y días / venideros que en secuencia se arrastran / mientras rumia el sentimiento los años / impasibles vividos en medio del destrozo / de lo que parecía más digno de confianza / y se prestaba así más a la renunciación” ${ }^{2}$. Aquello que ante los ojos emerge como lo más valioso, no pocas veces resulta ser lo más frágil. Con razón su permanencia en el tiempo pareciera ser un milagro.

Dos son, por lo mismo, quizás las más profundas aspiraciones del hombre: encontrar un sentido radical a cada instante de la propia existencia, y tener la seguridad de que ese sentido encierra en sí la fuerza necesaria para permanecer como una isla en la que uno pueda sentirse a salvo. Se trata, en definitiva, de un cruce existencial entre lo caduco o contingente y lo perenne o necesario; una forma de vivir en el tiempo sin caer en la tentación de sucumbir ante su fuerza arrasadora, por mucho de que se sepa demasiado bien hasta qué punto se le pertenece.

Sin duda alguna existe también una especie de camino trasero por donde aparentemente se podría evitar el plantearse el dilema recién mencionado. Si uno se considera a sí mismo como una mera pieza más del mundo, si la cul-

2 Eliot, 2009: 125, vv. 75-80: "There is not end, but adittion: the trailing / Consequence of further days and hours, / While emotion takes to itself the emotionless / Years of living among the breakage / Of what was believed in as the most reliable- / And therfore the fittest for renunciation". 
tura se reduce a una cómoda plataforma a la que adaptarse sin ningún tipo de reflexión, entonces pareciera ser que aquellos deseos por un "más" indefinido no sería más que una confusión, un sinsentido. En ese caso, la comodidad de la repetición de formas repartidas a lo largo de las semanas llenaría sin esfuerzo los espacios en los que uno podría encontrarse consigo mismo. Estas estructuras existenciales están descritas de forma acertada por Heidegger en su párrafo sobre el "man", del que afirma: "ya no es él mismo; los otros le han quitado el ser" ${ }^{3}$ Y $Y$ esto es independiente del tipo de cultura que sea. La característica primordial de este modo de vida es la identificación más plena posible entre cultura y vida, existencia individual y sentir colectivo, con una rotunda falta de reflexión en su fondo. Se trata de la entrega de la propia libertad interior en aras de adoptar una forma exterior que responda de forma definitiva a la pregunta por el propio ser.

Mas esta opción de vida es, en el fondo, elitista. Es fácil recorrer el camino de todos mientras uno se encuentra a gusto o se es parte de la jerarquía del sistema - con las seguridades que esto conlleva-o, por lo menos, si se es uno más de los que están sobre la barca del Mediterráneo, sin percatarse de que en esos instantes hay otros muchos que se están ahogando entre las olas. Es fácil olvidar a veces que, como dice Rilke, "todos nosotros caemos" o que, por lo menos, podríamos caer. No es de extrañar que a los pobres que están en el agua les cueste un poco más aceptar el mundo como es. De esta

${ }^{3}$ Heidegger, 2006: 126: „Nicht es selbst ist, die Anderen haben ihm das Sein abgenommen“ (cursiva en el original).

${ }^{4}$ Rilke, 1955: 156. Herbst: „Wir alle fallen“. 
forma, en el momento en que la apariencia se presenta como la realidad total, sin ningún tipo de momento para la reflexión, lo aparente termina constituyéndose como medida de todo orden, dando cabida a las mayores manifestaciones de injusticia $y$, lo que es quizás peor, haciendo que surjan también muros dogmáticos que pretenden anquilosar lo que en sí mismo debería ser orgánico y, por lo mismo, vital.

Hay un segundo camino que, precisamente por ser supuestamente su contrario - los extremos tienden a juntarse-, termina dirigiéndose hacia ese mismo fin: el deseo desmesurado por la novedad y el rechazo consiguiente de todo lo heredado. La creatividad descontrolada del individuo y su crítica acerva a todo lo recibido lo llevarían a despreciar cualquier sombra de influencia de otros, convirtiéndose así en una existencia encerrada en sí misma. Sin embargo, en este caso tampoco es difícil identificar una especie de dogmatismo que le lleva a suponer, sin ningún tipo de argumentación, que lo surgido de las propias manos es siempre superior a lo de los vecinos; no se da cuenta el susodicho de que él mismo es un producto de causas anteriores, de una cultura y de unas personas determinadas, por lo que su teoría solo puede llevarlo al desprecio de sí mismo. Es por eso que todo camino de superación ha de pasar, de una forma u otra, por la aceptación del propio ser, aunque se rechacen muchos de sus aspectos. De otra forma podría terminar uno afuera del mundo que se quiere redimir. Tanto un anarquista materialista, como un pseudo-espiritualista demasiado místico, están asechados por esa tentación ${ }^{5}$. Se olvidan, entonces, de aquella frase de Eliot: "Sólo en el tiempo se con-

${ }^{5}$ Interesante es lo que dice al respecto F. Inciarte sobre los arameos. Cf. Inciarte, 2016: 36-42. 
quista el tiempo"6; sólo desde lo que cada uno es, se pude lo grar la trascendencia, la superación. Y algo similar hay que decir sobre aquellos que defienden una postura un tanto esquizofrénica de separar demasiado el mundo de lo profano de lo sagrado o trascendente, construyendo la proyección de dos mundos - uno real y otro aparente- que conviven sin tocarse; como si el bien y el mal fuesen categorías absolutas, incapaces de entremezclarse e, incluso, de cambiar aparentemente sus identidades. Apariencia y realidad están más íntimamente unidas de lo que a veces se piensa (Inciarte, 2016: $51-52)$.

Un verdadero artista, en cambio, es un ser en la encrucijada. En primer lugar, es alguien que por una decisión vital está siempre en una postura reflexiva frente a la realidad, guardando una cierta distancia en su relación con ella, ya que sabe muy bien que la apariencia no es más que la otra cara de lo real; pero se trata de una reflexión que, a su debido tiempo, lo sumerge más profundamente en la existencia. A la vez ha de ser consciente de que el ejercicio de su voluntad no basta para ser un buen artista, aunque éste sea un requisito necesario, como tampoco lo es el perfecto dominio de la técnica, por muy encomiable que esto sea. Sin genio, sin inspiración, sin gracia, no hay verdadero artista. La mera firma de Picasso no transforma unas cuantas líneas en una obra de arte, aunque sí les dé un valor de varios miles de euros. A la vez que el artista se encuentra en un permanente estado de búsqueda, ha de llenarse de paciencia y esperar el momento oportuno. Su postura reflexiva

${ }^{6}$ Eliot, 2009: 89, v. 97: "Only through time time is conquered". 
es siempre a la vez una disposición tentativa, un buscar ser encontrado por la inspiración, con el deseo de que ésta lo encuentre en vela, preparado ${ }^{7}$.

Como el escultor se apropia de la piedra para transformarla a través de su subjetividad, así todo artista se sirve de la vida y quiere elevarla a un nivel superior, más absoluto. Sin embargo, así como la roca lo sigue siendo por muchas cinceladas que reciba, así también la vida — lo que ha sido descrito como sucesión fragmentaria de momentos- es también vida en la obra de arte. Pero esto es tan solo una parte de verdad. Pues, como describe Inciarte aludiendo al momento de la Aufhebung hegeliana, a través del arte se nos devuelve una vida condensada, la inmediatez de la mediación artísticoreflexiva (Cf. Inciarte, 2016: 60-61). Hay en la obra de arte lograda una forma, una unidad, que va más allá de la mera conjunción de elementos dispares (palabras, colores, etc.), que la dotan de un ser propio capaz de mantenerse por sí mismo en el devenir de la cotidianidad del tiempo. Más que una mera armonía, lo que muchas veces es sólo un artificio para crear un "pseudoarte" que deriva en un esteticismo, se trata de la objetivación externa de una sensibilidad interna o, si se quiere, la subjetivación de la realidad objetiva y aparentemente neutra, en cuanto lo interno de esa sensibilidad no se da por separado de la objetividad, sino simultáneamente. Es el devenir mismo, como todo en la vida, lo que produce la obra de arte, pero, en este caso, se trata de una forma de emerger primigenia, en la que el mismo surgir del objeto es la consolidación del sujeto en cuanto tal $-\mathrm{y}$ viceversa—, lográndose una

${ }^{7}$ Cf. Inciarte, 2016: 104. El conflicto del artista está muy bien descrito por F. Inciarte en torno a la figura de Hölderlin y a su poema An die Parzen. Cf. Inciarte, 2012: 39-43. 
unidad perfecta entre lo objetivo y lo subjetivo, el qué y el cómo. Es por eso que la obra de arte guarda una cierta analogía con un organismo: un ser con vida propia que, sin embargo, necesita determinadas condiciones externas a ella para su gestación y su sobrevivencia (Cf. Niemeyer, 1962: 287). Una vez que el artista ha dado a luz a una nueva obra de arte, éste ha de dejarla ser, distanciarse de ella con una pudorosa reverencia, a la vez que sigue con su vida "corriente" y tentando a los dioses para conseguir una vez más su gracia.

La vida de todo artista está quizás más que ninguna otra traspasada por la posibilidad cierta del error. Inciarte lo expresa de la siguiente forma: "el fracaso es algo que pertenece a la misma esencia de la creación artística como una amenaza constante" (Inciarte, 2012: 115). Los criterios objetivos y subjetivos para valorar un "algo" como obra de arte son escurridizos, en primer lugar, porque no es fácil medir con fórmulas exteriores un ser que tiene su propia vida, sobre todo si agota en sí mismo todas las posibilidades de su especie. También porque muchas veces el ser humano, demasiado atormentado por el trajín del tiempo, no es ya capaz de adoptar una disposición interior activa de condensación y sorpresa ante el milagro de lo artístico. Hans Urs von Baltahsar describe esta situación afirmando que "las obras de arte pueden morir cuando son atravesadas por demasiadas miradas sin espíritu" ${ }^{\text {. }}$ Pero visto desde una perspectiva más profunda, se podría decir también

${ }^{8}$ von Balthasar, 1961: 21: "Kunstwerke können sterben, wenn sie von zuviel geistlosen Blicken getroffen werden, auch ein gewisses Strahlen von Heiligkeit kann verdumpfen, wenn es auf lauter stumpfe Gleichgültigkeit auftrifft“. 
que la misma estructura fundamental de toda obra de arte se asimila a la de un error. ${ }^{9}$

Según Heidegger, justamente cuando "lo que está a la mano" (lo Zuhandene) no puede cumplir más su objetivo — cuando, por ejemplo, el martillo, por estar estropeado, no sirve para clavar clavos- es cuando uno se ve obligado a pensar sobre el martillo mismo, volviéndose consciente de algo que, por estar adormecido por la costumbre, se realiza normalmente sin reflexionar (por ejemplo, clavar). Pero todavía hay más. La ruptura de la cadena de medios y fines hace de pronto que uno reflexione también sobre la estructura del mundo y su sentido, devolviéndolo con más fuerza a aquella vida en la que todo se suele dar de forma inmediata. Un fallo es una grieta por la cual se atisban unas relaciones dadas por supuestas que, sin embargo, nos superan completamente y pueden dejarnos en un cierto desconcierto (Cf. Heidegger, 2006: 69-76). Algo similar ocurre de forma mucho más dramática con la muerte, sobre todo cuando se presenta de forma sorpresiva; cuando se contaba con alguien para una cita, pero no viene porque ha desaparecido.

Una obra de arte tiene una estructura similar. Chocar con ella significa, de pronto, romper las intrincadas relaciones de fines y medios que suelen componer el tejido de toda vida o superar las categorías que le permiten al hombre conocer la realidad, llevándolo a preguntarse por el sentido o identidad de lo que está percibiendo y, por lo mismo, de todo el mundo. ¿Qué es esto? ¿De dónde le viene su fuerza a esta "cosa" que es capaz, de pronto, de

${ }^{9}$ Esta idea se inspira en el capítulo de Inciarte sobre el error y el pecado original. Cf. Inciarte, 2016: 73-78. 
robar mi atención y, de algún modo, frenar el ritmo de mi cotidianidad? El arte moderno y de vanguardia, como dice Inciarte, va más allá en cuanto plantea la pregunta por la misma identidad del arte, volviéndose así reflexivo como la misma filosofía ${ }^{10}$. ¿Es esto arte, o un error, una pérdida de tiempo o el intento desesperado de un loco? Hace algún tiempo ocurrió en Alemania que una señora de limpieza destruyó una obra de arte que costaba millares de euros por haber limpiado una tela de araña. Toda obra de arte está siempre en el precipicio entre el todo y la nada. Incluso aquellas obras que se transforman en mera decoración también se pueden decir que han fracasado, y quizás más rotundamente, porque al haberse identificado con el mundo, no tienen ya ningún tipo de fuerza que lleve a reflexionar sobre ellas. Las obras maestras lo son precisamente porque pareciera que, a pesar del abismo que las rodean, de la gran posibilidad de haber sido un tremendo fracaso, son un verdadero mundo lleno de vida. De vida, porque, así como los fallos en el trato inmediato con el mundo permiten asomarse a sus estructuras más profundas, así también esas obras artísticas devuelven al hombre una madurez interior para comprender mejor la propia vida y el mundo que lo rodea; en ellas están condensadas muchas posibilidades existenciales, como un todo necesario y orgánico, pero no de forma discursiva o lógica, sino muchas veces como un golpe intuitivo o una condensación de la reflexión.

${ }^{10} \mathrm{Cf}$. Inciarte, 2004: 74: “...se ha llegado a un punto en que, después de la revolución del arte del siglo XX, el propio arte ha asumido esa tarea de reflexión, [...] en sus manifestaciones superiores se ha convertido repetidamente en filosofía del arte". El contexto de la cita es la crítica de Inciarte a la aseveración de Hegel de que la filosofía ocuparía el lugar del arte. 
¿No es acaso, hasta cierto punto, esa combinación de contingencia y necesidad lo que se busca en la propia vida? Nadie se contenta con ver en la propia existencia un mero producto fortuito de un encuentro entre dos seres humanos llamados "padres"11; por el contrario, la mayoría de las veces vence el empeño por escribir una biografía con sentido que le dé un contenido al propio nombre y una consistencia a las decisiones que se van tomando. Pero, a la vez, permanece también esa incertidumbre existencial del artista, de no saber si al final logrará dar a luz una obra maestra, un milagro de la inspiración, o, más bien, se hundirá en el más rotundo fracaso. Como todo artista, se tiene bien presente la propia muerte, porque una buena obra de arte sólo se conoce una vez terminada (Cf. Inciarte, 2016: 107). Así toda vida, cuando es verdaderamente reflexiva y no un mero engranaje de un mundo cerrado y en funcionamiento, está rodeada de abismos: es el arte de vivir.

La revelación cristiana, me parece, se comprende mejor desde este punto de vista, es decir, considerando la existencia humana como una constante apertura a las interrogantes radicales, y haciendo de la vida un proyecto que, por su audacia, nunca parece estar conseguido del todo. Existe una combinación frágil y misteriosa, hasta el punto de que es una cuestión teológica abierta, entre la libertad y la gracia, el saberse ya salvado, redimido por un don que sobrepasa totalmente al hombre y, a la vez, ser conscientes de que se ha de luchar con todas las fuerzas por recibir dignamente lo que se es regala-

\footnotetext{
${ }^{11}$ Cf. von Balthasar, 1973: 457: "Die Frage (wer bin ich?) wird um so quälender, als der Einzelne seine Existenz auf das zufälligste Ereignis der Welt zurückführen muss: den Geschlechtsakt zweier Individuen“.
} 
do, haciendo propio lo recibido ${ }^{12}$. Un cristiano es un artista de su propio ser, porque es capaz de dejarse llevar por el poder de lo alto. La máxima tensión por obrar desde y con la gracia le hacen navegar en todo momento entre lo necesario y la contingencia, el todo y la nada.

La fragilidad intrínseca de toda obra de arte está dada por su contingencia, superada, eso sí, por esa fuerza misteriosa llamada gracia o genio, y que la lleva a ser una existencia necesaria. Así también el cristiano, poseedor de una llamada superior que lo eleva de forma inmerecida por sobre el caminar monótono de tantos, no ha de perder la conciencia de su valor efímero o el carácter contingente de su ser. Por qué algunos son encontrados por el don de la fe y otros no, es un misterio que ningún pensamiento humano puede desentrañar, como tampoco un artista puede explicar de forma consistente y totalmente lógica cómo ha llegado a crear una obra de arte lograda. Más bien sólo sabe que, si intentase manipularla y ser infiel a la inspiración, si se dejase comer por el éxito de su obra, sin querer separarse de ella para que goce de su propia vida a lo largo de los años, entonces terminaría renunciando a su propia existencia y destruyéndose a sí mismo. Más que goce y admiración, el arte sería entonces motivo de sufrimiento y locura. Ya que, como explica von Balthasar, toda obra de arte, en cuanto quiere realizar una Forma propia, es un intento por mostrar el propio ser y, a la vez, en cuanto se quiere dar una visión más profunda de la realidad, es también un "esconderse", que ha de

${ }^{12}$ Cf. Inciarte, 2016: 257-266. En este capítulo, Inciarte habla sobre Henri de Lubac y la relación que existe entre naturaleza y gracia en su teología. 
llevar al artista a no imponerse en su obra de arte ni a considerarse importante, sino a dejarla ser lo que es ${ }^{13}$.

La vida cristiana consiste, según el mismo teólogo suizo — quien se basa en diversas corrientes filosóficas y teológicas-, en una representación dramática de condiciones peculiares. Elige el drama porque en él pareciera ser que se da la unión más íntima posible entre la vida entendida como la cotidianidad del propio yo, y su trascendencia en la obra artística. A diferencia de otras artes en las que la obra está destinada a permanecer fuera de su creador, desarrollando una vida propia, en el teatro se da una identificación fuerte entre el yo vital-cotidiano y el papel que le toca representar. Sin embargo, no hay que engañarse. "Quien sólo puede representarse a sí mismo, no es un actor" ${ }^{14}$. Es decir, sólo en cuanto el actor va más allá de su mera existencia, puede trascenderse y conseguir la sublimidad deseada de toda obra de arte. Su vida cotidiana ha de ser condensada por una nueva forma superior, que, al sobrepasarla, no se reduce a ella, sino que ha de explicarse más bien desde arriba, desde afuera o desde lo otro.

¿Quién puede darle al hombre el papel que ha de actuar en la vida? Y aún más, ¿no pareciera, quizás, que hacer de la propia vida una representación terminaría por cubrirla con un velo de apariencia, de insinceridad, condu-

${ }^{13}$ Cf. von Balthasar, 1961: 426: "Deshalb wird der Künstler schon darum sich in seinem Werke ebenso sehr verhüllen als enthüllen: gewiss, sofern er seine Anschauung gestaltet, enthüllt er etwas von sich selbst, sofern er aber tiefer verstandene Welt zeigen will, wird er sich selber unwichtig und behandelt sich als bloßes Medium, das als solches nicht aufdringlich zu werden strebt“.

${ }^{14}$ von Balthasar, 1973: 273: „Wer nur sich selbst spielen kann, ist kein Schauspieler“. 
ciéndola al "man" heideggerano, sí tal vez más auténtico, pero igual de artificial y esclavizador? ¿Cómo seguir el consejo del ya citado teólogo de dejar a un lado los papeles indeterminados, que sólo son ropajes de nuestro yo, para llegar a un yo que en sí mismo no puede ser intercambiado por ningún otro y portador de un papel dramático, no ya en el campo del teatro, sino de la propia existencia? ${ }^{15}$ ¿Cómo puede el hombre conseguir esa forma íntima y propia que le lleva a poseerse y a desarrollar su vitalidad propia, que es a la vez regalo y elección fundamental? ${ }^{16}$ Naturalmente que sólo Aquél que es dador de vida puede concederle al hombre su papel dramático existencial, sin que esto le lleve a caer en un automatismo inerte o en la esclavitud del pobre ante el poderoso. La propia vida es ya en sí misma gracia, porque el ser humano no se crea a sí mismo, y sólo Dios, en cuanto creador de su libertad, es capaz de actuar en la intimidad de su ser con la gracia, siempre y cuando el hombre permanezca abierto a Él. Esa apertura existencial hacia aquello que proviene de lo alto no significa nunca un dejarse llevar de forma inconscien-

${ }^{15}$ Cf. von Balthasar, 1973: 604: „Es galt wegzunehmen von einer Beliebigkeit der “Rolle”, die dem farblosen Ich nur wie ein zufälliges Kleid übergestülpt ist und jederzeit durch eine andere vertauschbar bleibt, um zu einem "Ich" zu gelangen, das als solches unverwechselbar bestimmt und so erst zum Träger einer wahrhaft dramatischen Rolle im Bereich nicht des Theaters, sondern der Existenz befähigt ist".

${ }^{16}$ Cf. von Balthasar, 1961: 21-22: „Was ist er (der Mensch) ohne Lebensform, das heisst ohne Form, die er für sein Leben gewählt hat und in die er sein Leben ein- und dahingiesst, damit es zur Seele dieser Form und die Form zum Ausdruck seiner Seele werde, keine fremde Form, sondern eine so intime, dass es lohnt, sich damit zu identifizieren, keine aufgezwungene, sondern eine von innen geschenkte und freigewählte, keine beliebige, sondern die einmalige persönliche, das individuelle Gesetz?“. 
te, sino más bien, justamente porque solo en la libertad y desde el interior de uno mismo se puede llegar a ser aquello que se es realmente, es que es necesaria la permanente reflexión, el raciocinio discursivo sobre la propia existencia, que mantiene vivo el papel dramático-existencial; siempre es necesario decirle que sí a ese papel, superando el yo natural (es la teología de san Pablo sobre el hombre viejo y el hombre nuevo), mientras se lo va haciendo cada vez más algo propio; en toda vida humana hay atisbos de plenitud pero, por su finitud, todo hombre ha de elevarse una y otra vez. Así se dan simultáneamente una decisión fundamental, la apertura misma hacia Dios, y una libertad constantemente ejercida en la cotidianidad de la vida. La reflexión constante sobre la fe, a pesar de ser ella un don que nos supera radicalmente, es como la inseguridad del artista ante el misterio de la inspiración. Cómo él, el cristiano está llamado a combinar la más excelsa magnanimidad por saberse portador existencial de un don completamente inmerecido y misterioso, con la más plena humildad frente a una obra de arte que, si bien ha salido de las propias manos, lo ha hecho con una fuerza que no le pertenece (Cf. von Balthasar, 1973: 272-274).

Además, Dios con su Encarnación ha dado un paso más. Es lo que expresa Eliot también en sus Cuatro cuartetos: "La insinuación adivinada apenas, el don sólo a medias comprendido, es la Encarnación" ${ }^{17}$. Tal es el valor que le da Dios a la libertad humana en el juego existencial de la vida que, una vez seguido el camino del pecado - aquel error y fracaso existencial que, sin em-

${ }^{17}$ Eliot, 2009: 137, vv. 258-259: „The hint half guessed, the gift half understood, is Incarnation“. 
bargo, despierta en el hombre también la reflexión sobre su propio papel en este mundo (Cf. Inciarte, 2016: 73-78)—, Dios ha querido ser uno de nosotros en este mundo y hacer de su existencia el mejor intérprete del drama humano. En Cristo, Dios y hombre verdadero, se da el equilibro perfecto entre el don mismo de Dios y la más plena aceptación libre del hombre. En él se cumple a la perfección aquel milagro del que habla von Balthasar de cuando el actor olvida toda la técnica que domina y pasa a ser realmente aquél a quien representa ${ }^{18}$. Dios es realmente hombre, sin dejar de ser realmente Dios (Concilio de Calcedonia) (Cf. Inciarte, 2016: 129-130). Él es, por lo mismo, la más perfecta unión entre forma y contenido; Él es, como forma, su propio contenido ${ }^{19}$.

Sin embargo, el fin de la vida de Cristo sume al hombre en la más profunda incertidumbre. La desfiguración de Jesús en la $\mathrm{Cruz}^{20}$ es, como ya decía san Pablo (Cf. 1 Co 1, 23), el gran escándalo, la gran locura para la razón existencial del hombre, siempre preguntándose por su papel en el mundo. Aquél que parecía ser la Forma más perfecta de existencia, está ahora colgando de unos maderos y trasformado en aquel que nadie quiere mirar

18 von Balthasar, 1973, p. 273: „Es gibt das Wunder, dass ein Schauspieler seine völlig beherrschte Technik vergisst und der ist, den er spielt. Das Wunder ist selten (...). Der Weg über das Können muss zurückführen zum scheinbar unbewussten Sein, sonst war er ein Irrtum“.

${ }^{19}$ Cf. von Balthasar, 1961: 445: „Christus aber ist die Form, weil er der Inhalt ist. Das gilt absolut, denn der einzige Sohn des Vaters ist er, und was immer er gründet und stiftet, ist nur durch ihn sinnvoll, nur auf ihn bezogen und von ihm erhalten lebendig“.

${ }^{20}$ Cf. von Balthasar, 1987: 50: „Die Ungestalt des Kreuzestodes“. 
(Is $33,3$.$) . Todo pareciera indicar que la obra de arte ha fracasado, que se$ trata de un error, que los abismos lo han tragado para siempre. Su silencio en la Cruz pareciera confirmarnos en esta opinión.

¿O no será más bien que el hombre, demasiado inmerso en sus propias categorías, ya no es capaz de distinguir lo que es una obra maestra? Es que la muerte de Cristo, la figura desfigurada de la Cruz, es la manifestación más sublime de la verdadera Forma, el fin de toda apariencia y la revelación plena del verdadero sentido del hombre. Cristo en la Cruz no sólo es prototipo para toda otra vida, sino, además, en la medida en que entrega su Forma, es también la única vida que no se agota en sí misma y que es capaz de dar vida a todas las demás; sin dejar de ser una existencia particular, es, a la vez, universal. ${ }^{21}$ Se podría hablar de una forma formarum existencial. Precisamente la más grande gracia del hombre, la mayor plenitud a la que puede llevar su existencia y, por lo mismo, su libertad, es el darse cuenta de que su forma no está llamada a encerrarse en sí misma y a gozarse de sus propios logros, sino a donarse y a ser, a su vez, gracia para todos los demás. La trascendencia de su ser, la superación de todas las limitaciones contingentes de su libertad y de su existencia en cuanto finita, se logra sólo en la medida en la que se dé cuenta de que la Forma de Cristo es la negación de su propia Forma; así como él se negó haciéndose hombre por amor a nosotros (Cf. Fil 2, 8), así el hombre sólo llegará a ser divino, obra consumada, en la medida en que se niegue a sí

${ }^{21}$ Cf. von Balthasar, 1987: 89: „Er selbst wird aufgrund seines Todes, worin er sein LeiblichInnerstes öffnet und seinen Geist hingibt, zum universalen, ohne aufzuhören, der PartikulärEinmalige zu sein“. 
mismo y se atreva a llevar una vida como Dios; y Dios es donación, Amor. Solo entonces aquello que perecería ser el mayor fracaso de la existencia y la pérdida para siempre del propio ser — la muerte-, se puede transformar en la consumación más perfecta del vivir: entrega radical y definitiva a Dios (Cf. von Balthasar, 1987: 85-86). Nadie tiene un amor más grande que el que da su vida por aquellos que ama (Cf. Jn 15, 13). Así sí que hay verdadera resurrección, donación permanente, y sorpresa incesante ${ }^{22}$.

Naturalmente este papel existencial es superior a todo hombre. A pesar de los grandes ideales, de poseer la gracia abundante para mantenerse aferrado al papel correspondiente, siempre se vuelve a caer en lo que podría llamarse la vida original, el yo no artístico o encerrado en sí mismo. Así como la reflexión puede llevar muchas veces al hombre a un dramatismo más vívido y existencial, también puede llenarlo de escepticismo y hacerle caer en la desolación y en la desesperanza. Más que mal, nunca logrará vencer radicalmente su finitud; cada momento de sorpresa puede transformarse en un error y la contingencia de su vida seguirá tentándolo para que busque una forma auténtica que no necesite de nadie, ni siquiera de la inspiración. Por eso es que la reflexión es tan necesaria para llevar una vida verdaderamente humana. Mas Hans Urs von Balthasar viene a recordar, citando a una crítica de teatro suiza, que la mejor definición de un artista es que es el único ser a quien se le

${ }^{22}$ Cf. Inciarte, 2016: 141-142, donde Inciarte deja abierta la posibilidad del conocimiento discursivo en la bienaventuranza futura; de otro modo, no existirían las sorpresas. 
exige de más ${ }^{23}$. Y un cristiano, como hemos visto, es un artista. Además, Inciarte tranquiliza al hombre con su afirmación de que sólo existen grados de realidad, de que nunca lograremos la plenitud sin más (Cf. Inciarte, 2016: 57 y 87). No hay que olvidarse de que existe un único Dios. La contingencia del ser humano, por muy unido que esté a la divinidad, no dejará de ser contingente. Eliot lo expresa de forma poética: “[...] la acción justa / es también liberación del pasado / y del futuro. Para casi todos / nosotros ésta es la meta que nunca / alcanzaremos; nosotros que sólo / logramos no ser derrotados / porque hemos perseverado; nosotros, al fin satisfechos si nutre / nuestra reversión temporal / [...] / la vida de una tierra con sentido" ${ }^{24}$. Se trata de mantenerse vivo en la perseverancia, con sinceridad interior, reconociendo la propia caducidad y abriéndose al Todo. Esa es la condición del verdadero milagro. Sólo cuando el hombre capta de forma profunda que, siendo radicalmente contingente, el amor de Dios lo crea, lo salva y lo hace ser algo necesario, es cuando consigue dar con el propio fin de su existencia. Sólo entonces la liturgia, como inmediatez de lo mediato y manifestación más plena de la unión con Dios, tiene verdadero sentido y no es un conjunto de costumbres muertas. Porque ante la gracia radical de Dios hacia los hombres, como dice von Balthasar, que ya no es belleza, sino verdadera gloria, no se

${ }^{23}$ Cf. von Balthasar, 1973: 273: „Er sei das einzige Wesen, von dem man zuviel verlangt werde“. La cita es de Brock-Sulzer, 1954: 210.

${ }^{24}$ Eliot, 2009: 137, vv.268-278: “(And) right action is freedom / From past and future also. / For most of us, this is the aim / Never here to be realised; / Who are only undefeated / Because we have gone on trying; / We, content at the last / If our temporal reversion nourish / (Not too far from the yew-tree)/ The life of significant soil". 
puede responder con mera admiración y sentimientos sublimes, sino únicamente con adoración ${ }^{25}$. O como escribe Eliot casi al final de sus Cuatro cuartetos: "Con la atracción de este amor y la voz de la Llamada / no dejaremos de explorar / y el fin de nuestra búsqueda será / llegar donde comenzamos / y el lugar conocer por vez primera" ${ }^{26}$.

"El fin es de donde partimos — dice también el poeta inglés, y prosigue. Y cada frase, / cada oración lograda (donde cada palabra / está cómoda y toma su lugar / apoyando a las otras, la palabra / que ni es apocada ni ostentosa, el intercambio/ natural de lo antiguo y lo nuevo, la palabra / común, exacta pero no vulgar, / la palabra formal, no por precisa pedante, / el entero conjunto bailando en armonía), / cada frase, cada oración, es fin y es principio" ${ }^{27}$. Si bien estos versos no se pueden aplicar de forma justa a este escrito, sí que condensan de forma precisa el sentido de una obra de arte y, por lo mismo, el ideal para una vida lograda. Es que la armonía de una vida sólo

25 Cf. von Balthasar, 1987: 52: „Angesichts dieser Gnade schlechthin, die nicht mehr Schönheit, sondern Herrlichkeit kundtut, ist nicht mehr nur Verwunderung und Entzücken erfordert, sondern Anbetung“.

${ }^{26}$ Eliot, 2009: 159, vv.266-270: "With the drawing of this Love and the voice of this Calling / We shall not cease from exploration / And the end of all our exploring / Will be to arrive where we started / And know the place for the first time".

${ }^{27}$ Eliot, 2009: 157, vv. 240-251: "The end is where we start from. And every phrase / And sentence that is right (where every Word is at home / Taking its place to support the others, / The word neither diffident nor ostentatius, / And easy commerce of the old and the new, / The common word exact without vulgarity, / The formal word precise but not pedantic, the complete consort dancing together) / Every phrase and every sentence is an end and a beginning". 
puede medirse desde su final: la muerte. Esa es la razón de que, para Eliot, todo poema sea un epitafio ${ }^{28}$, y que para nosotros la muerte de Cristo, junto con su Resurrección, sea fuente de gozosa esperanza. Porque, si bien es cierto que "todos caemos", también es verdad que hay Alguien que sostiene en sus manos, de manera infinitamente suave, ese caer. ${ }^{29}$

\section{Bibliografía empleada}

H. U. von Balthasar, Herrlichkeit. Eine Theologische Ästhetik, Band I: Schau der Gestalt, Einsiedeln, 1961.

—, Epilog, Einsiedeln, 1987.

—, Theodramatik. I. Prolegomena, Einsiedeln, 1973.

E. Brock-Sulzer, Theater. Kritik aus Liebe, München, 1954.

T. S. Eliot, Cuatro cuartetos (edición bilingüe), Madrid, 2009 (traducción de E. Pujals Gesalí).

M. Heidegger, Sein und Zeit, Tübingen, 2006.

F. Inciarte, Imágenes, palabras, signos. Sobre arte y filosofia, Pamplona, 2004

—, La imaginación trascendental en la vida, en el arte y en la filosofía, Pamplona, 2012

-, Cultura y verdad, Pamplona, 2016.

H. Müller, Herztier, Reinbeck, 1994.

M. Niemeyer, Untersuchungen zur Ontologie der Kunst, Tübingen, 1962.

${ }^{28}$ Cf. Eliot, 2009: 159, v. 252: "Every poem (is) an epitaph (...)”.

${ }^{29}$ Cf. Rilke, 1955: 156. Herbst: „Und doch ist Einer, welcher dieses Fallen / unendlich sanft in seinen Händen hält“. 
Gaspar Brahm

R. M. Rilke, Sämtliche Werke Band I, Wiesbaden, 1955.

Gaspar Brahm Mir

gasparbm@gmail.com 